\title{
Supplemental material: Methane emissions from an oil sands tailings pond: A quantitative comparison of fluxes derived by different methods
}

\author{
Yuan You ${ }^{1, \S}$, Ralf M. Staebler ${ }^{1}$, Samar G. Moussa ${ }^{1}$, James Beck ${ }^{2}$, Richard L. Mittermeier ${ }^{1}$ \\ ${ }^{1}$ Air Quality Research Division, Environment and Climate Change Canada (ECCC), Toronto, M3H 5T4, Canada \\ ${ }^{2}$ Suncor Energy Inc., Calgary, T2P 3Y7, Canada \\ ${ }^{\S}$ Now at Department of Physics, University of Toronto, Toronto, M5S 1A7, Canada \\ Correspondence: Ralf M. Staebler (ralf.staebler@canada.ca)
}

Supplemental Figures

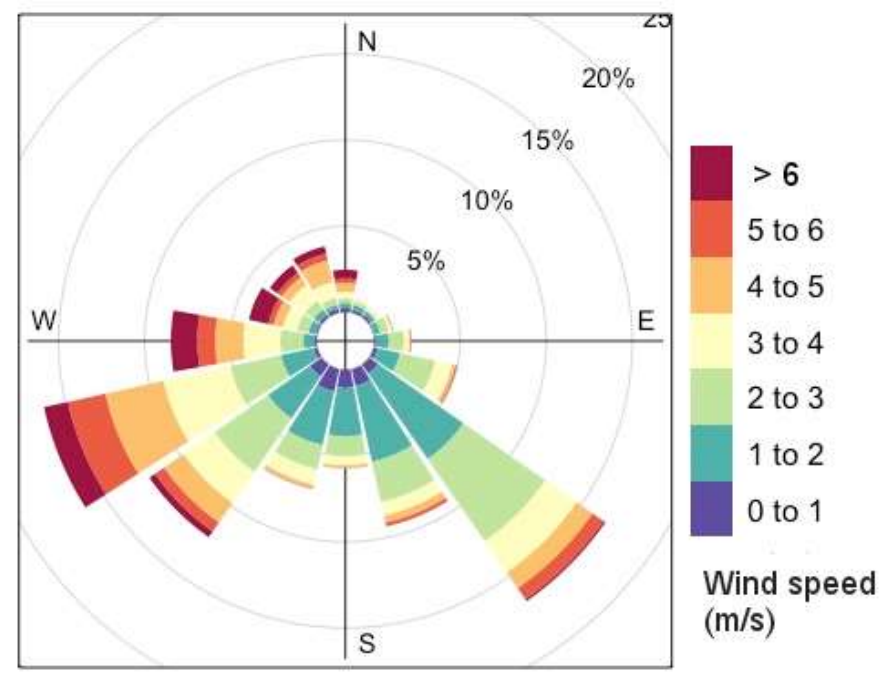

Figure S1 The wind rose for the entire measurement period. The color labels the wind speed $(\mathrm{m} / \mathrm{s})$. The radius represents the frequency of the wind in each direction bin. 


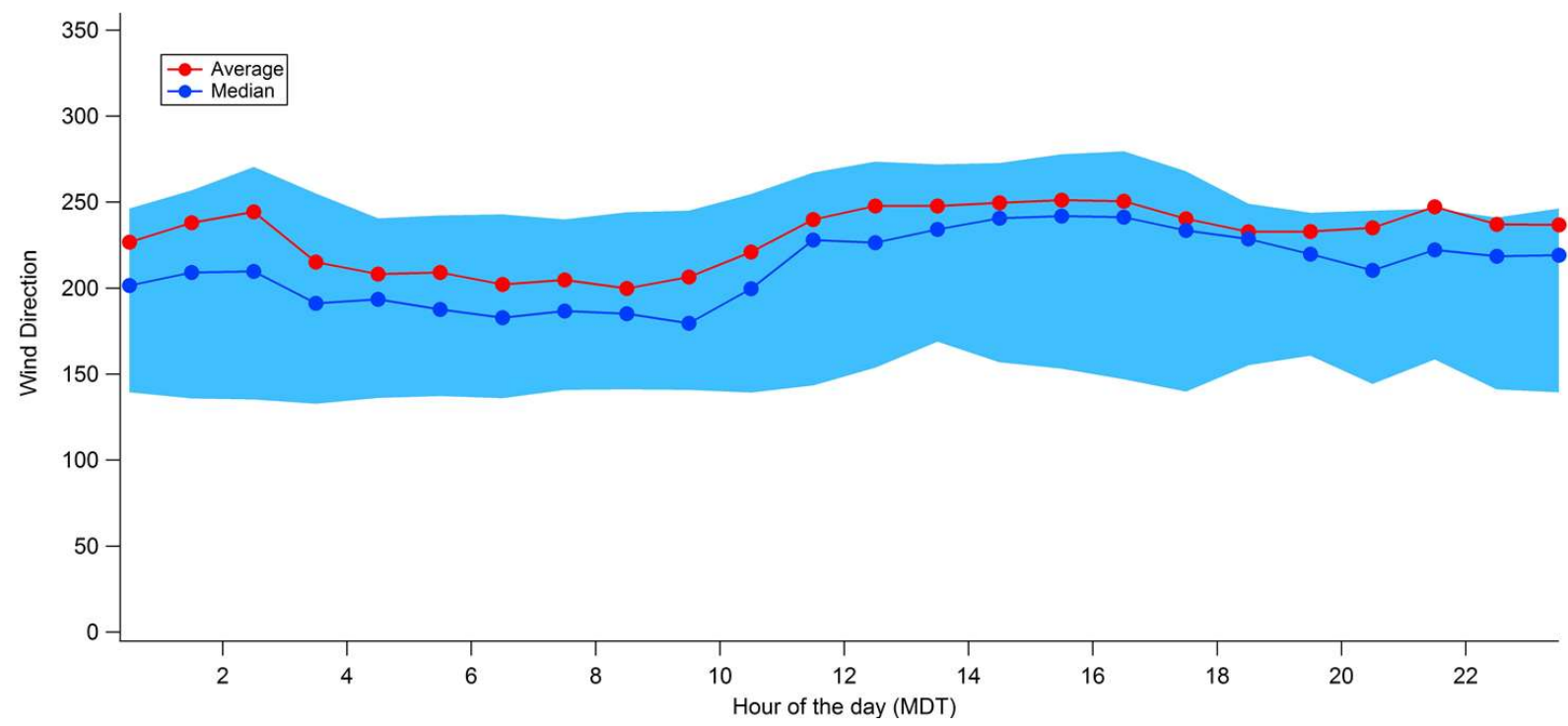

Figure S2 Diurnal variation of wind direction during the study. MDT = Mountain Daylight Savings Time. 
(a)

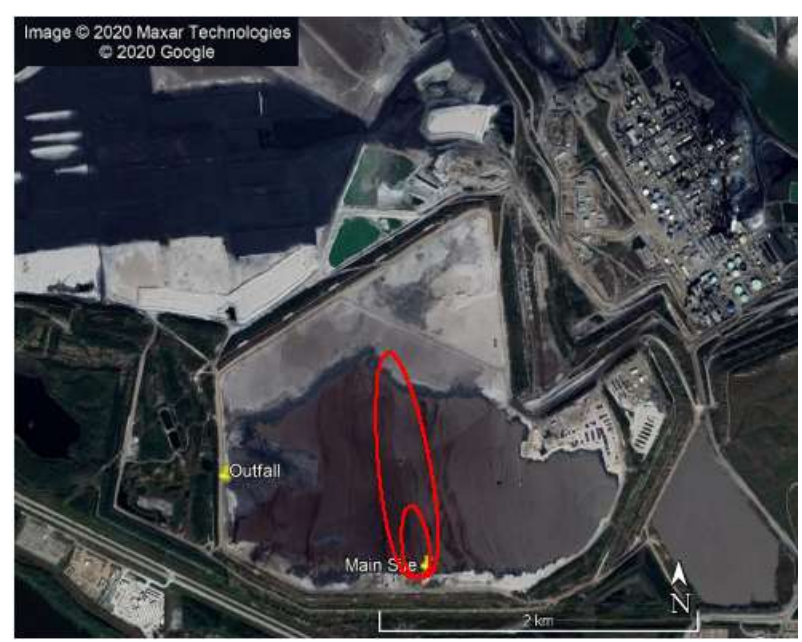

(b)

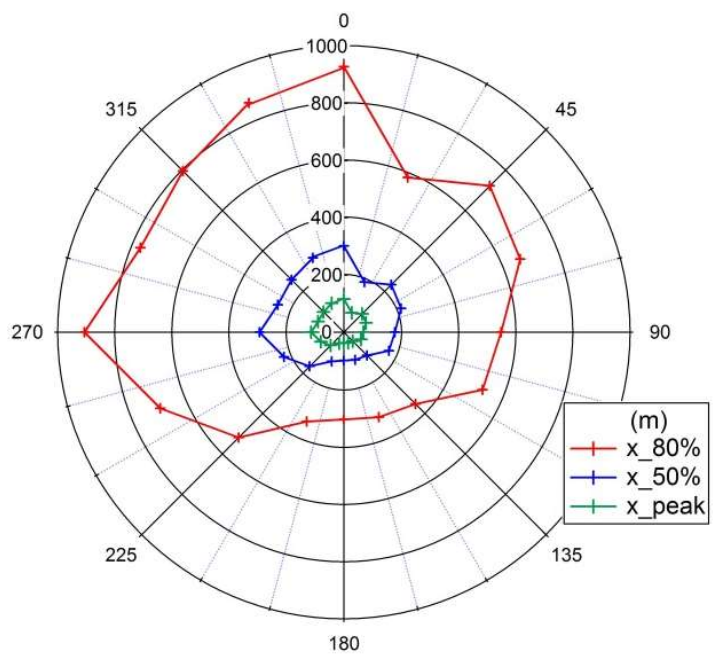

Figure S3 (a) $80 \%$ and $50 \%$ flux contours of the observed EC flux over a half-hour period. Footprints were calculated every 30 minutes using the Flux Footprint Prediction (FFP) algorithm

[http://geography.swansea.ac.uk/nkljun/ffp/www/index.php], which bases its algorithm on Kljun et al. (2015). (b) The complete rose plot with peak, $50 \%$ and $80 \%$ contribution distances for the measured EC fluxes. Radius shows the distance in meters. Angles are the wind direction (true North). 

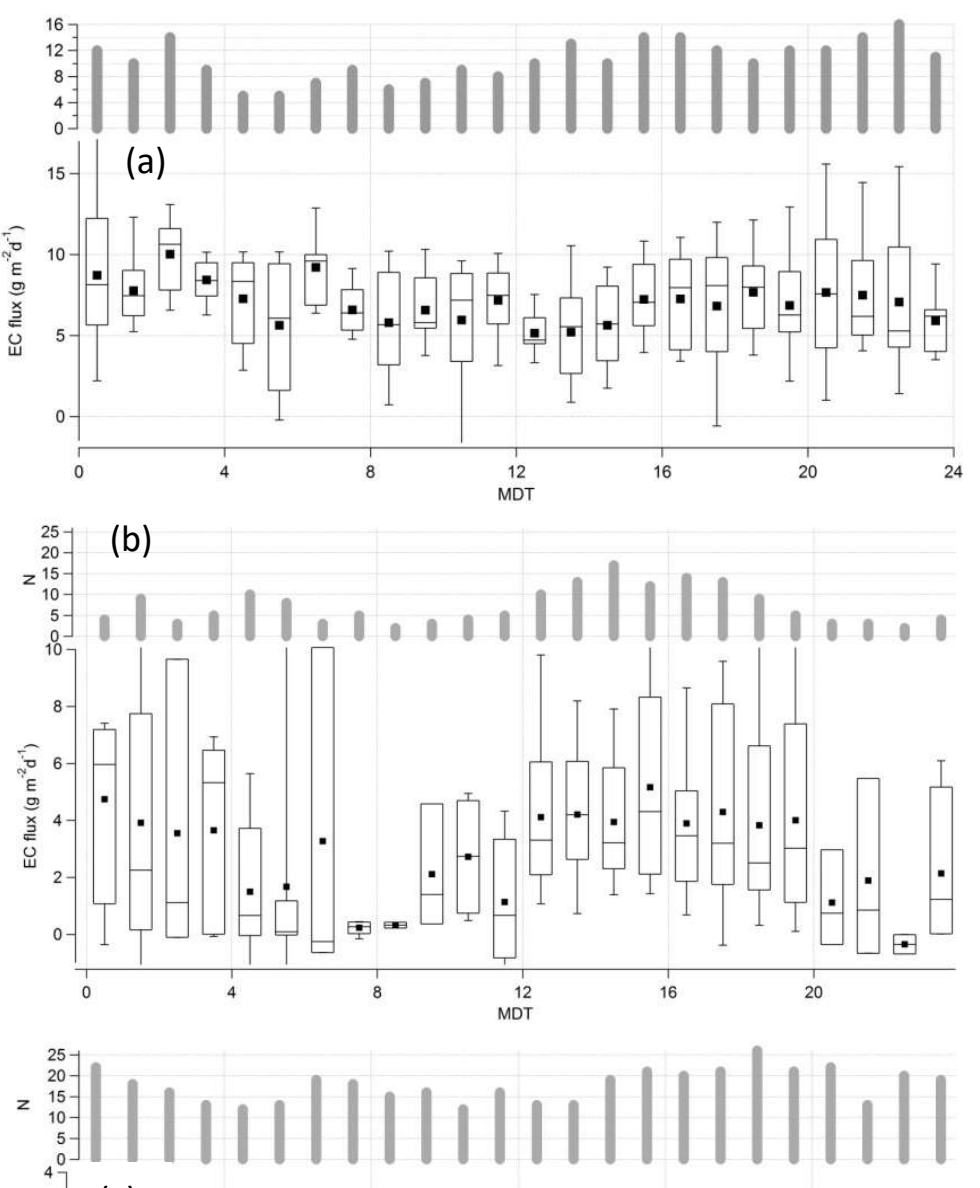

(c)
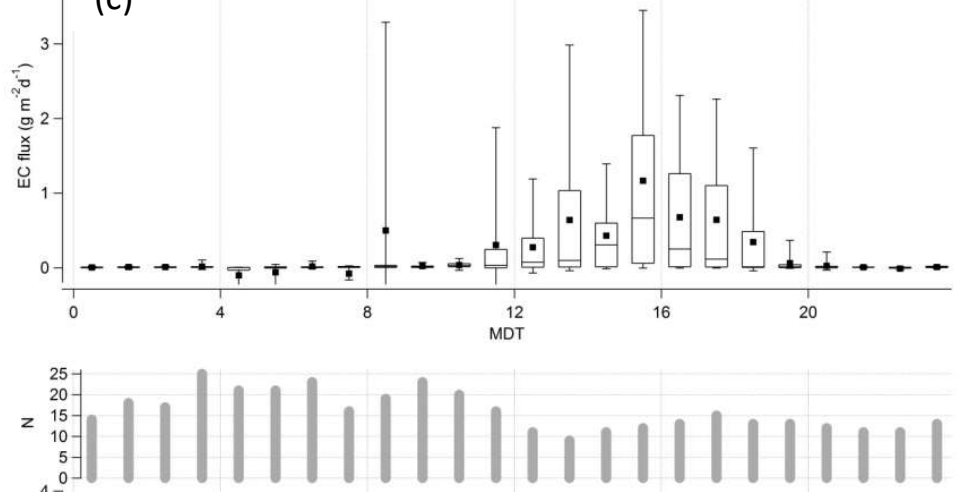

(d)

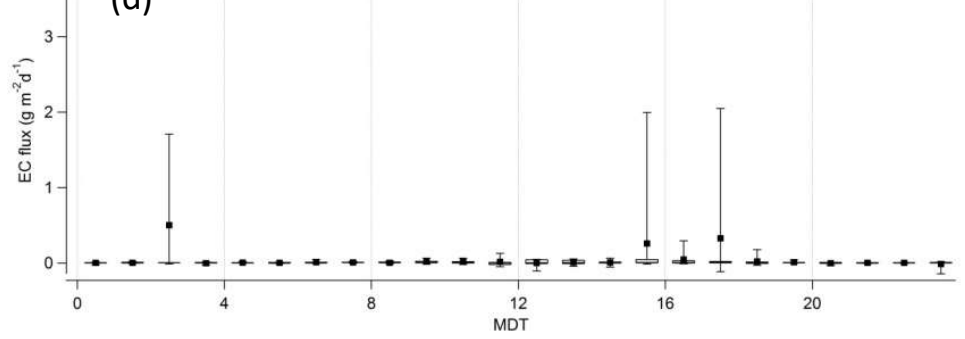

Figure S4 Diurnal variation of EC flux (bottom) and number of $\mathbf{N}$ half-hours in each hour bin (top). (a) Wind direction (WD) $\geq 286^{\circ}$, or $W D \leq 76^{\circ}$; (b) $258.75^{\circ} \leq \mathrm{WD}<286^{\circ}$; (c) $213.75^{\circ} \leq \mathrm{WD}<258.75^{\circ}$; (d) $123.75^{\circ} \leq \mathrm{WD}<146.25^{\circ}$. $\mathrm{MDT}^{\circ}=$ Mountain Daylight Savings Time. 

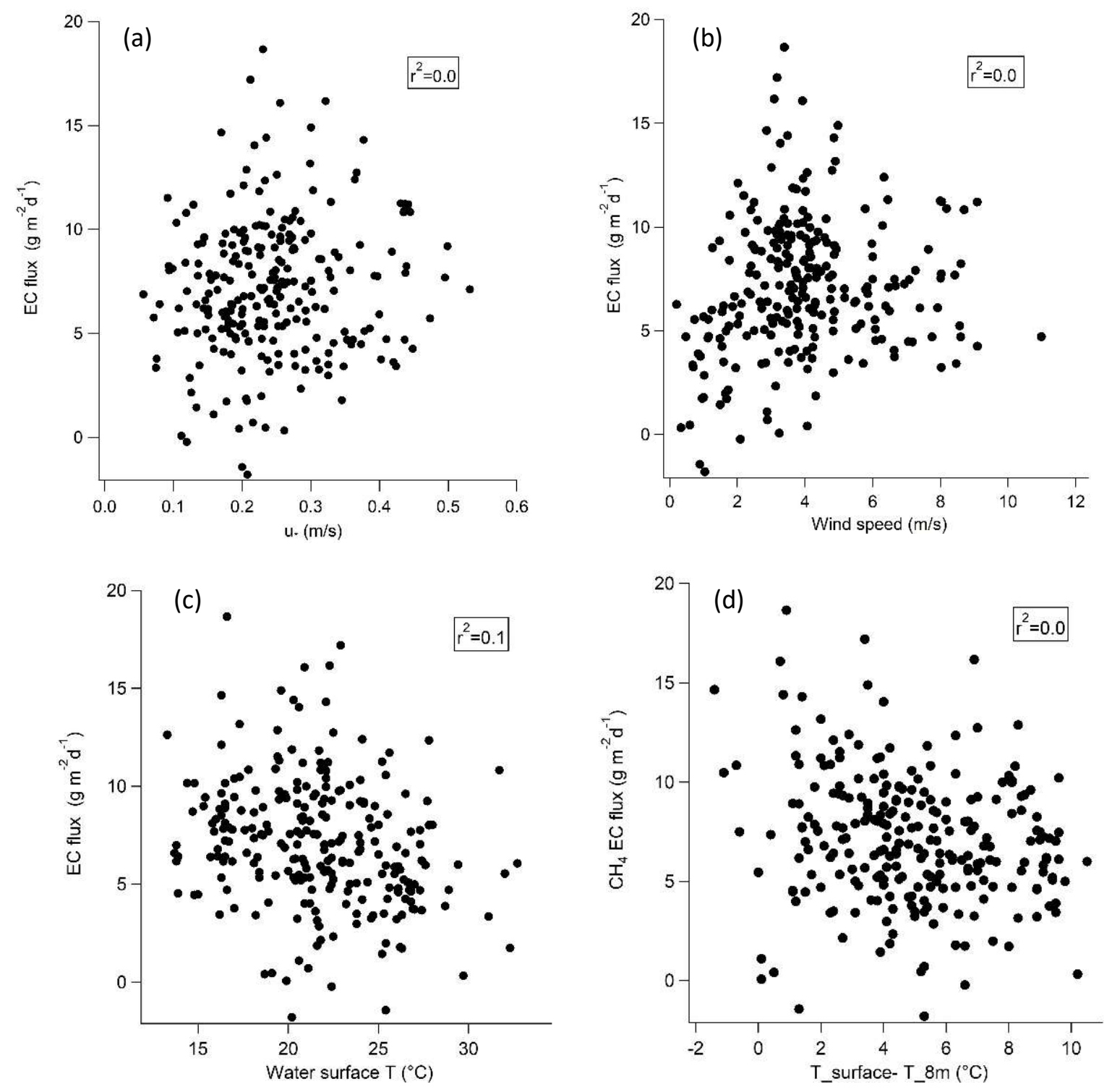

Figure $\mathrm{S}_{5} \mathrm{CH}_{4} \mathrm{EC}$ flux when the wind came from the pond direction as a function of (a) $\mathrm{u} *$; (b) wind speed; (c) water surface temperature; (d) temperature difference between water surface and $8 \mathrm{~m}$. 


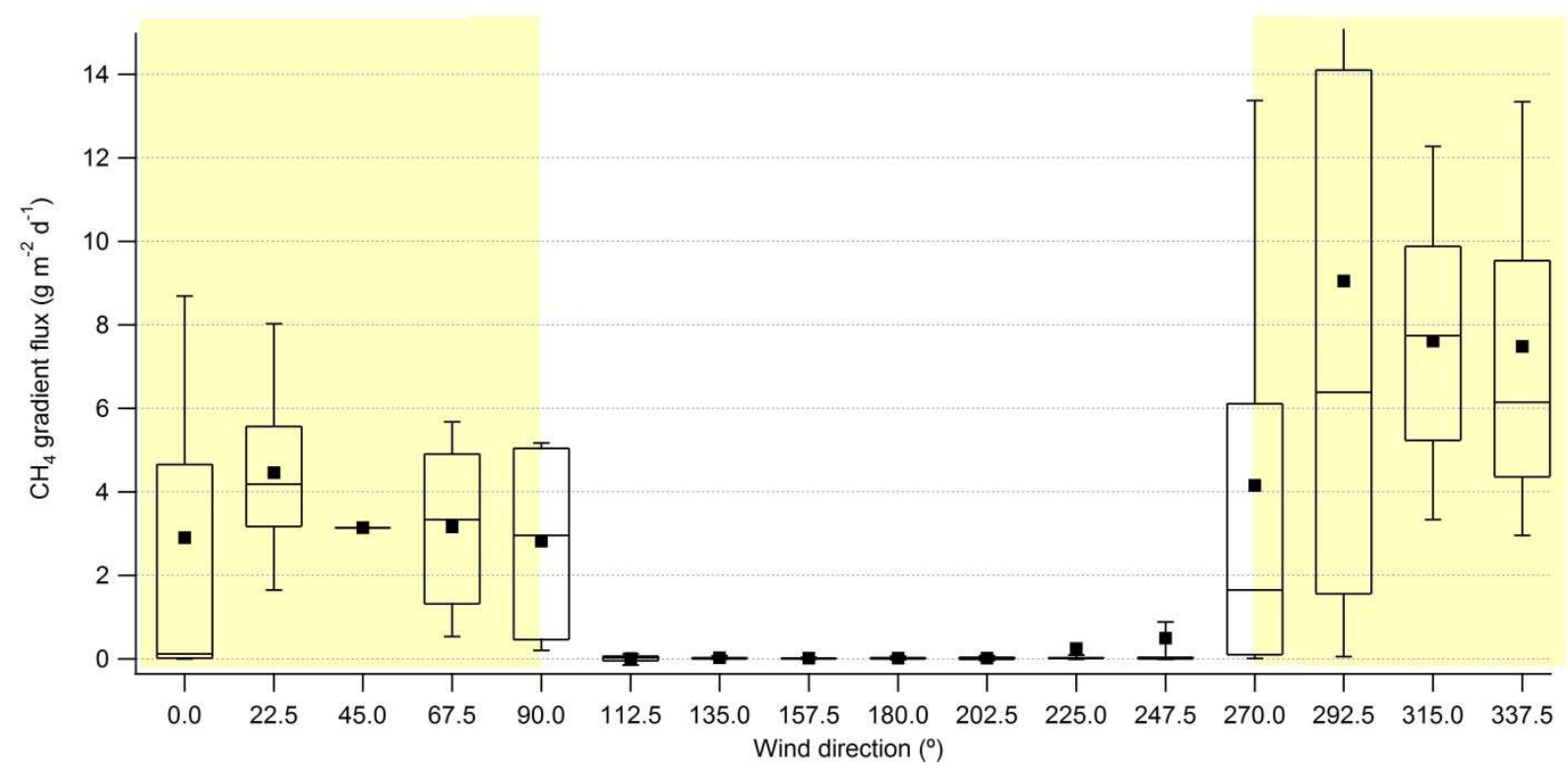

Figure S6 Gradient flux of $\mathrm{CH}_{4}$ as a function of wind direction, yellow shades indicate wind directions from the pond.

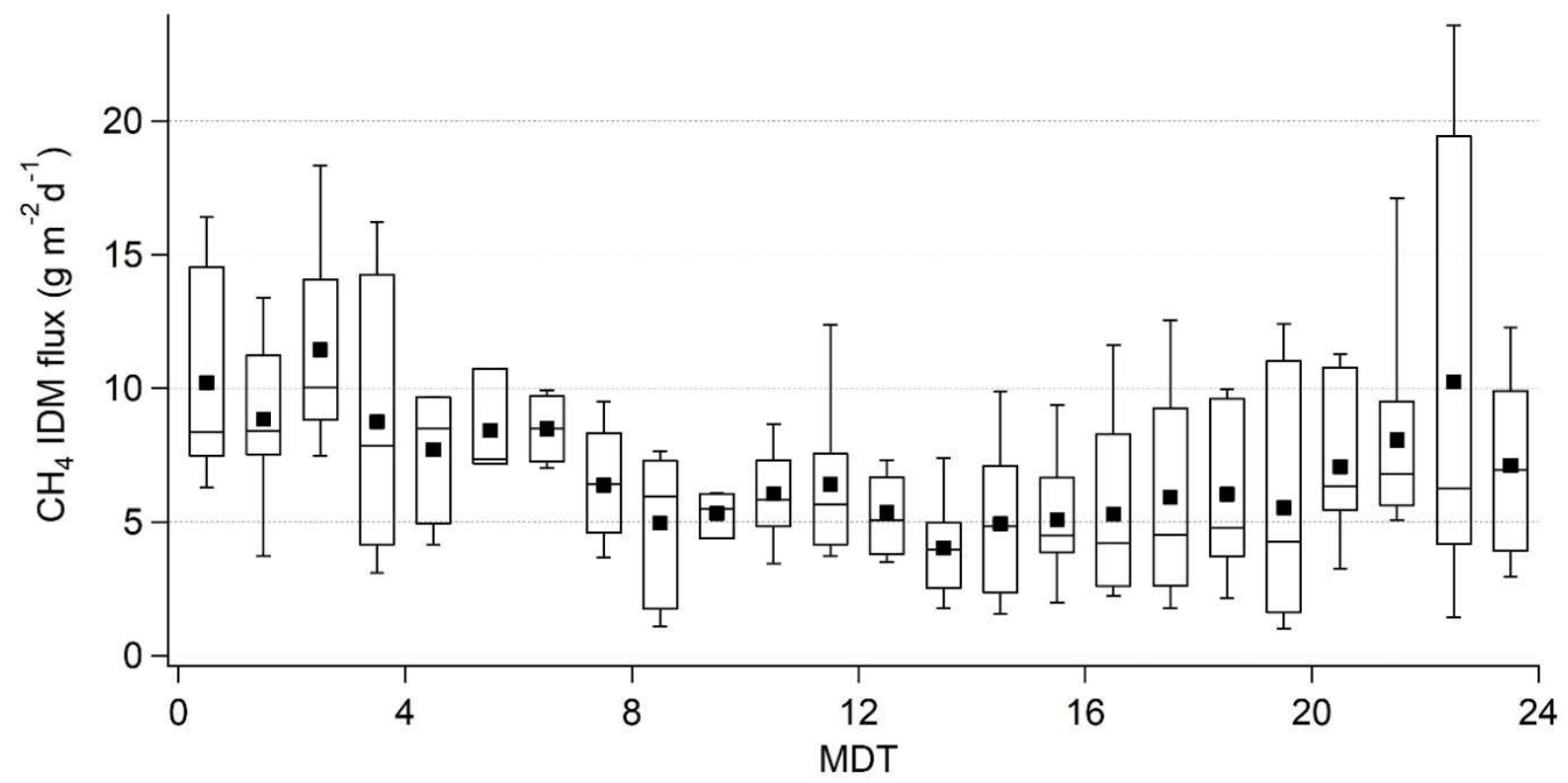

Figure S7 Diurnal variation of IDM flux. MDT = Mountain Daylight Savings Time. 


\section{Supplemental Table}

Table $\mathrm{S} 1 \mathrm{CH}_{4}$ gradient flux $\left(\mathrm{g} \mathrm{m}^{-2} \mathrm{~d}^{-1}\right)$ results with two approaches for calculating $S_{c}$.

\begin{tabular}{|c|c|c|c|c|}
\hline$\left(\mathrm{g} \mathrm{m}^{-2} \mathrm{~d}^{-1}\right)$ & $\mathrm{Q}_{2} 25 \%$ & median & Q_75\% & mean $^{\mathrm{a}}$ \\
\hline Variable $S_{c}$ & 2.6 & 4.6 & 7.9 & $5.7 \pm 1.6$ \\
\hline Constant $S_{c}$ & 1.9 & 4.5 & 6.7 & $4.8 \pm 0.9$ \\
\hline
\end{tabular}

a Errors with the mean fluxes are calculated with a "top-down" error estimation approach, using the average of standard deviations of fluxes from five periods when the fluxes were relatively steady. 